\title{
STRUCTURED ASSIGNMENT PEDAGOGY: AN SAP ENTERPRISE SOFTWARE DEPLOYMENT
}

\author{
Roger L. Hayen, Phoenix One Ltd., roger.hayen@outlook.com
}

\begin{abstract}
The SAP Enterprise Central Component (ECC) Enterprise Software is included in the curriculum of many universities. Various course teaching materials are shared through the SAP University Alliance (UA) program. These materials are primarily keystroke oriented step-by-step learning resources for various business process transactions. Faculty implementing enterprise software in their curriculums are confronted with the challenge of the work product to be prepared by students for submission for grading. This investigation looks at the deployment of structured assignments that clearly identify the expected results to be completed, organized, and submitted in an Integrated Business Experience (IBE) course. The cognitive learning styles of students furnish a foundation for imparting structured assignments in this course. The goal of this investigation is to provide these examples, which may act as a springboard for other faculty to consider as they develop assignments for either SAP ECC software or other keystroke step-by-step learning materials.
\end{abstract}

Keywords: Structured Assignments, Enterprise Software, Assignment Pedagogy

\section{INTRODUTION}

Faculty have struggled with their expectations of student results from the experiential, hands-on assignments from Window-based applications since the advent of this software as portrayed in various textbooks that include one such at that for Comprehensive Lotus 1-2-3 Release 4 for Windows [5]. This situation has continued with the inclusion of SAP Enterprise Software (SAP ES) experiences in university curricula since the introduction of this integrated business processing software in the late 1990's. Enterprise software is commonplace in managing business operations [6]. SAP ECC is an excellent learning platform as it provides knowledge of the type of automated business processing conducted using enterprise software. Antonucci, et al. [2] provide a review of the adoption of the SAP ES within educational institution. From their work, an expectations dilemma continues as students explore the processes of SAP ES by following a keystroke narrative for the steps of a business process, such as sales and distribution (SD). These activities are very detailed in the keystrokes the students are to follow. For SAP ES, the step-by-step instructions are more rigid than with most of the desktop productivity software tools. However, they lack structure in what the student prepares for submitting to verify they completed the assignment and for grading. A typical arrangement by many faculty relative to the SAP ES application is to have students submit a copy of the entire keystroke instruction document they follow with results recorded in that document [8]. Current examples of these instructions are represented by the chapters of Global Bike Incorporated 2.11 (GBI) [17] and of Essentials of Processes, Systems, and Information with SAP Tutorials [13]. Those instructions have students observe document numbers and data values they enter or are created by SAP ES. The course materials lack a structure of what the students should record and/or interpret when they perform the instructions of the keystrokes for a set of business processes. For example, GBI Chapter 4 on Sales and Distribution is a 48 page document of instructions a student would submit - a lot of paper for a single assignment. Whereas, this chapter asks students to record observed data values, this is no other guidance in the structure provided for their overall work product. This is active learning from the fact students do follow the keystroke instructions. However, when students submit their copy of the instructions, there is no verification a student actually executed these instructions. Comments made by students indicate they view SAP ES as very easy as all they need to do is just type the keystrokes. This provides a false view of the integrated business processes and the complexity behind them that is embodied in enterprise software.

The lack of structure for the activities of the assignments from keystroke-based learning has continued as illustrated by the Access database text of Adamski, et al. [1]. That is, in the past 20 years, the keystroke-based instructions continue to be refined, whereas structure of the assignment results remain essentially unchanged. The students can do the keystrokes, but there is a lack of specificity in what should be prepared for submission for grading. That is, a more structured and guided assignment expectation. It is granted that the results for assessing assignments are at the 
discretion of the faculty. For example, is it just the completed Access database file? Or, does it include intermediate results and explanations, such as a description of the SQL statements used with an Access query. This is the area where structure can be increased by the teaching faculty to guide the students in completing the assignment for grading. This guidance is the structuring of the expectation of the student work product. The purpose of this paper is to provide an example of one pedagogical design for increasing the structure of student responses. A structured learning approach specifies the details of how students are to capture assignment results, which are submitted for grading electronically. Clearly, other approaches or derivative approaches exist and are deployed by various faculty across different information technology courses. The goal of the paper is to trigger faculty thoughts and ideas for examining how keystroke-based assignments are structured for student learning responses.

\section{BACKGROUND}

The background for the example course pedagogy is a dichotomy of (1) structured and unstructured assignments and (2) the Integrated Business Experience (IBE) course in which structured learning assignments are applied. The research on structured assignments furnishes the cognitive learning framework. The IBE course is the SAP ES application course with keystroke oriented assignments which provides the environment for the deployment of this cognitive learning pedagogy.

\section{Cognitive Learning}

Structured teaching-learning increases the guidance in student preparation. This is guidance that many of today's students have come to expect [15]. Structure assignments are shown to positively impact student learning, especially for students who are not ready for self-directed learning [4]. They report the, "Results of our analyses confirm that students will prefer to complete assignments that correspond with their cognitive style." Even those students who are more innovative and exhibit a higher self-efficacy are more conformable so that, "... an instructor should ensure there is a full understanding of the assignments and sets of instructions." The research of Cate and Dyman [3] provide results that students prefer and express a higher level of self-efficacy and less anxiety on assignments that match their cognitive style for their extent of self-directed learning. A challenge is to create structured assignments that meet the learning requirements of student who are not ready for self-directed learning, while accommodating those who are ready for self-directed learning. The deployment of structured learning is further supported by the use of course syllabi with clear expectations [15] [16]. This paper examines two methods of providing the structure for directed learning with keystroke-oriented software application assignments in a single course, which focuses on SAP ES and its integrated business processes embodied in that application software. The purpose is to increase the learning of the underlying business processes, rather than just having a student successfully complete keystrokes.

\section{Learning Environment}

The IBE course includes a high level of keystroke-oriented assignments related to learning about the integration of business processes through the application the SAP ECC (aka SAP ERP, depending on the current marketing used by SAP SE, formerly SAP AG) enterprise software. A typical IBE course using the SAP ES is described in prior work [7] [11]. The IBE course is segmented into two components. One component focuses on transaction processing, whereas the second component focuses on the analytics and decisions making of business intelligence (BI). The first component is bottoms-up learning of individual transactions and the specific processing steps, such as those steps for processing an individual customer order from the initial order entry to the collection and recording of the cash received from the customer. This is the end-to-end customer order to cash $(\mathrm{CO} 2 \mathrm{C})$ business process stream. It includes the intermediary steps of the pick, pack, ship, billing, and cash collection of the customer order. The transaction processing segment makes use of GBI course materials. The second component is top-down business decision making. This uses the ERPsim manufacturing simulation [12]. Student learn higher level transactions that include entering material or product selling prices, releasing batches of material orders to vendors, and entering a forecast of expected sales. These are business process transactions that capture decision inputs from students, which are processed within ERPsim. The ERPsim simulation requires a team environment. It is vital that students are prepared for these team interactions. While much of the bottoms-up transactions are done individually, students are still required to interact with their team in completing the final elements of each assignment. This builds team dynamics that help to prepare students for the ERPsim course component. The structured learning for 
GBI is more specifically directed than for ERPsim. GBI teaches the concepts of integrated business processes at the individual transaction level of SAP ES. ERPsim furnishes learning the concepts of analysis and decision making at the strategic and managerial level of SAP ES processes. Each is important in understanding the importance of business process integration within enterprise software. Hence, the assignments deploy a different structure design for these two course components. Overall, the business processes learning experience of students in IBE courses is very positive and well received [9] [10] [12]. The following sections describe the two IBE primary perspectives and illustrate the inclusion of structured assignments to enhance self-directed learning, while augmenting the grading of those assignments. This investigation examines the use of a structured learning approach to the GBI exercises and the activities surrounding the ERPsim simulation. It illustrates one method for adapting course materials to increase the structure of the respective assignments. Structure course materials for GBI and ERPsim are explored separately, because of the differences in the learning focus of those two SAP ES component in an IBE course. The goal is to present these examples so they may be deployed by other faculty or server to trigger ideas for structuring similar learning materials for use in teaching courses that include the use of SAP ES or similar enterprise software.

\section{GBI TRANSACTION PROCESSING}

The transaction processing segment of the IBE course use the GBI course materials, which are globally available through the SAP AG University Alliance [14]. The IBE course includes only GBI chapters one through six. This transpires over the first one-third of the courses and is limited by that time constraint. These chapters provide a solid introduction to the fundamentals of the low-level business process transaction, including CO2C. Chapters 1 and 2 are a conceptual and navigation introduction to SAP ES. Chapter 3 focuses on the organization structure within SAP ES. Chapter 4 Sales and Distribution (SD) comprises the CO2C transaction process steps. Chapter 5 encompasses the purchase order to payment (PO2P) processes. Finally, Chapter 6 is production planning (PP) processes that include examples of a bill of materials (BOM). The examples of structure learning presented here are from Chapters 3 and 4. These examples portray the method used to embrace structured learning activities within those course materials and occur after students have mastered the logon and transaction navigation activities.

GBI Chapter 3, Organization Structure Global Bike Inc., presents an additional challenge in creating the structured learning activities. This is a most important topic as the unique key fields of the transaction records in the database of SAP ES have the organization units as their key data elements. For many transactions, specifying the organization structure data is the first component of a set of the steps that carry out the details of as set of transactions, such as $\mathrm{CO} 2 \mathrm{C}$. This chapters as provided by the SAP UA (2013) contains no active learning components. It is a read-only learning component. The chapter was significantly re-written and revised to include coordinated active learning of the organization structure (aka org structure, in "SAP speak"), because of the importance of this with most SAP ES transaction processes. Structured learning examples are incorporated from this revision.

The structure learning activities are partitioned into the three component of (1) the chapter narrative with keystroke instructions, (2) the student answer sheet for recording results to be submitted for grading, and (3) a team comparison requiring discussion of the results and also submitted for grading. Each of these individual learning activities is expressly identified by the use of an icon as a visual label which associates the desired action of the students. For the examples presented here, this identification links the three documents used with a structured learning experience.

An introductory narrative provides a lead in to the org structure of GBI 2.11 for the learning activities which follow. The narrative includes values of the key elements of the org structure. The first structured activity, identified by its icon of 3-1, is a template shown in Figure 1 in which students enter the hierarchical elements of the org structure. An identical template is provided in the student answer sheet with the same icon which is include in the document submitted for grading. The answer sheet document is the work product submitted electronically for subsequent grading. The numbered icons provide a direct connection between the assignment narrative and the student answer sheet. The answer sheet provides a much more compact method for recording the solution than having students record their answers on the narrative document

The assignment answer sheet (Figure 1) provides the logical org structure for GBI. This needs to be included in the configuration of the GBI dataset or client. The GBI client dataset is pre-configured, so the entries for configuration 


\section{Issues in Information Systems}

Volume 16, Issue II, pp. 17-26, 2015

of the org structure already reside in the client. The purpose here is to introduce students to the org structure and not to immediately move to configuration activities. However, students can verify the occurrence of the logical org structure within the SAP ES client.

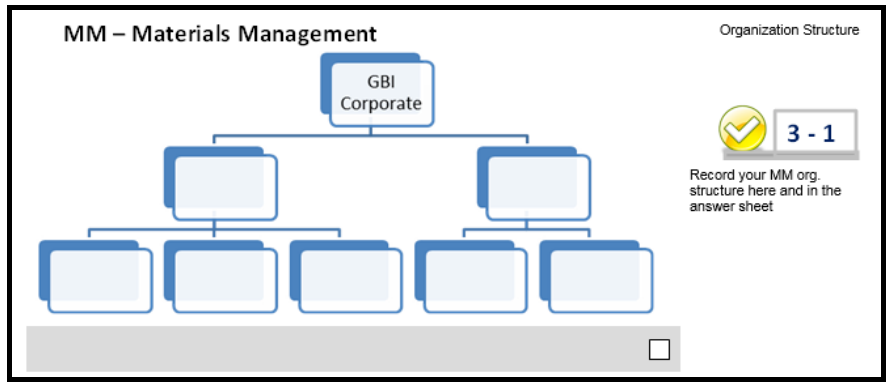

Figure 1. Designed Assignment for Recording the Logical Key Elements of the SAP ES Organization Structure

Figure 2 illustrates structured activity 3-3 where students follow a detailed set of keystrokes to display the org structure. Activity 3-3 (Figure 2) is the example from the keystroke narrative where students are provided the details of the structured assignment. In this example they are directed to do a screen capture. The student answer sheet (Figure 3) portrays how that answer document is designed to receive that screen capture and is a key component providing structure of the student work product.

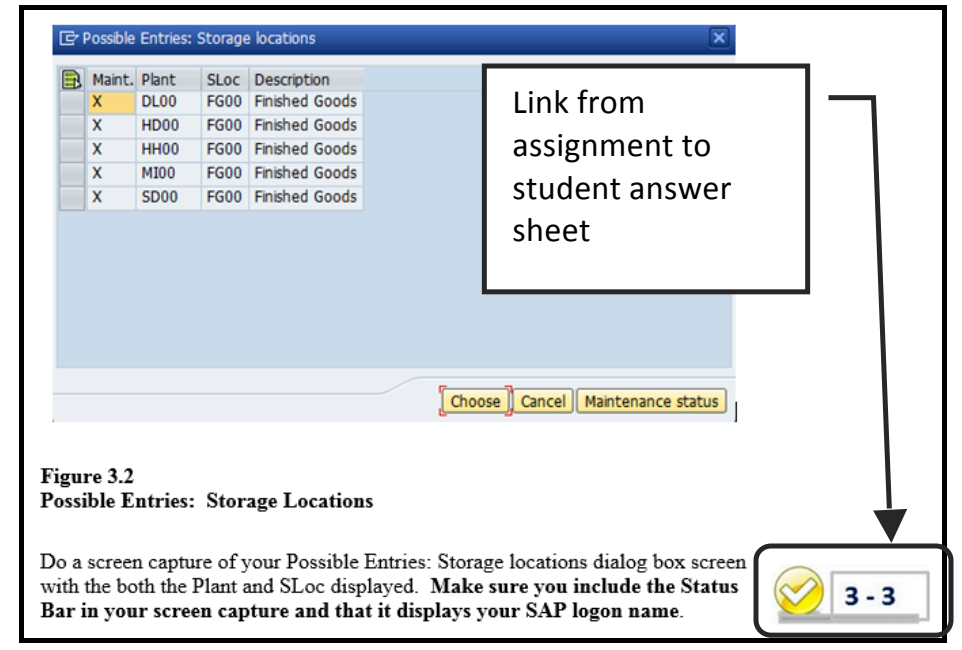

Figure 2. Chapter 3 Narrative and Structured Instructions for Capturing the Organization Elements Results as They Appear in the GBI 2.11 Instructional Materials

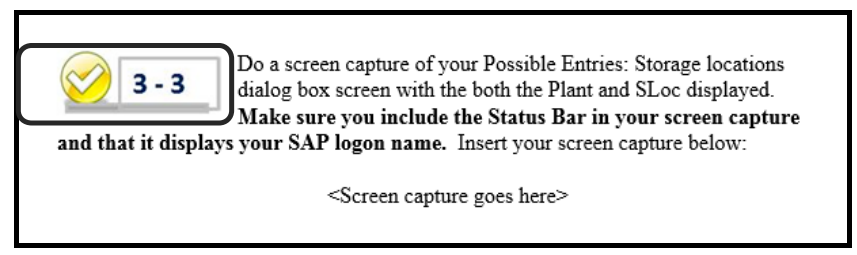

Figure 3. Chapter 3 Student Answer document structured to receive result

Finally, Figure 4 illustrates how the student completes the student answer sheet by inserting the screen capture. Also, Figure 4 demonstrates the manner in which students are required to display their SAP ES logon name in the status bar, which is located at the bottom of the SAP GUI screen. This is important for this and other screen captures as it verifies this work was completed using a student's assigned logon name. That is, one student cannot 


\section{Issues in Information Systems}

Volume 16, Issue II, pp. 17-26, 2015

share the same screen capture with another student. Each student has a unique logon name, so the screen capture must be done within that logon name. Is it $100 \%$ fool proof? No. However, the screen must be created using the individual student's logon name. The keystroke steps must be completed within that logon name in order to do this and other screen captures. Clearly, this inhibits the ability of one student presenting the file of another student as his/her own work by merely copying the entire assignment file and submitting it for grading.

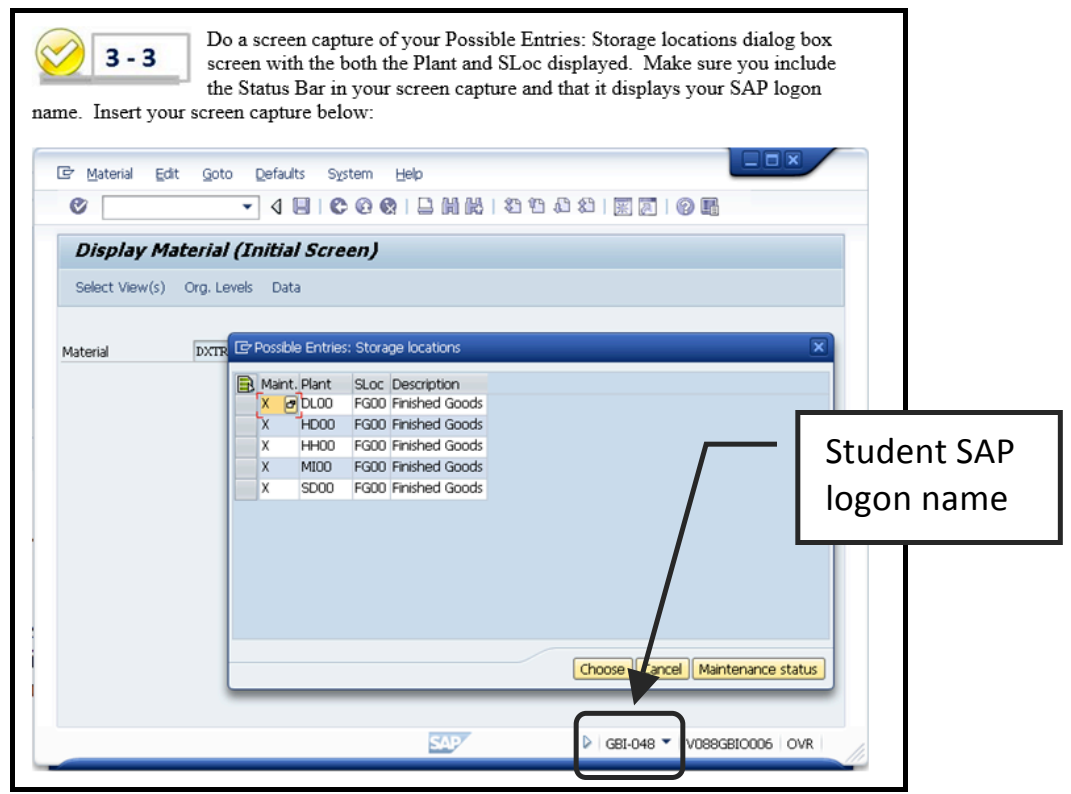

Figure 4. Completed Result in Student Answer Document

The IBE course teams build their interactions and dynamics through GBI transaction processing activities. Each team compares the results from its members to determine the similarities and differences in their answers and to explain their observations. This supports the self-efficacy dimension of cognitive learning. Figure 6 displays the Team Answer sheet or document with the team's observation and explanation. Whereas, in this example, the results are the same for all team members, this depends on the particular transactions. For instance, when SAP ES generates an internal document (IDOC) or database record for a transaction, then unique IDOC numbers are produced. (The IDOC number is a key field in the SAP ECC database.) The teams are expected to observe and explain these situations (Figure 5). The primary purpose of the Team Answer sheet is to get students to participate in a comparative discussion of individual results.

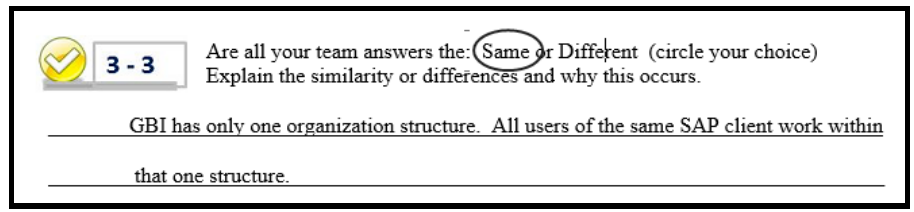

Figure 5. Completed Result in Team Answer Document

Figures 6 and 7 demonstrate the relationship between the Chapter 3 Narrative and its corresponding Chapter 3 Student Answer sheet for activity 3-9. This examples shows the look up of data values for a transaction and the recording of the specific values on the Student Answer sheet together with a screen capture to verify the data values are from the student's specific logon name. The Chapter 3 Student Answer sheet document consist of four (4) pages that structure the student assignment responses. This compares to 26 pages for the Chapter 3 Narrative. It is 85 percent less pages than the Chapter 3 Narrative document and represents a more condensed document for submission for grading. 

customer?

In the Sales Areas by Customer dialog box, select the last or bottom row of the available Sales areas and display its data in the Display Customer:

Company Code Area Data screen. Then, do a screen capture of this screen. Mispe sure you include the Stat

What is the Recoh. Account (that is Reconcilliation Account) number for this

How many different Sales Areas are there for Customer 17\#\#?

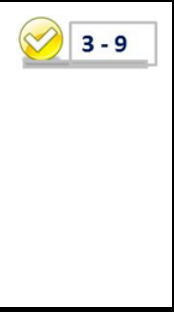

Figure 6. Chapter 3 Narrative and Structured Instructions for Capturing Results with Observed Data Values for Activity 3-9

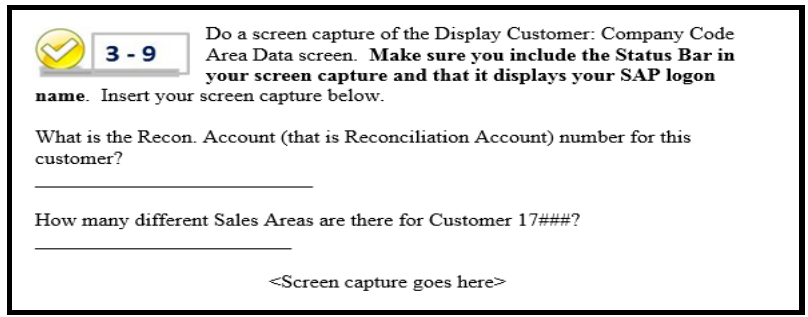

Figure 7. Chapter 3 Student Answer Document for Recording Results with Observed Data Values for Activity 3-9

GBI Chapter 4, Customer Order to Cash, includes the details of the steps for this lower-level transaction processing. Figure 8 is the Chapter 4 narrative for activity 4-4 that concludes with the creation of a Customer Standard Order and results in displaying the internally assigned number for that order. The Standard Order number uniquely identifies an IDOC created and stored in the SAP database for the order. Figure 9 illustrates the narrative for the Billing Document at activity 4-9 with its details and related IDOC. The results of the examples from the Chapter 4 Narrative are recorded in that chapter's Student Answer sheet document shown in Figure 10. Notice the Figure 10 examples portrays only a section of the Student Answer sheet for activities 4-4 through 4-9. It does provide a more robust view of the Student Answer sheet documents for capturing individual student results. The Chapter 4 Student Answer sheet document page length is reduced by 94 percent from the Chapter 4 Narrative for submission for grading. Again, this is a significant reduction of the document for grading when compared to the submission of the entire Chapter 4 Narrative into which the student results would have been embedded.

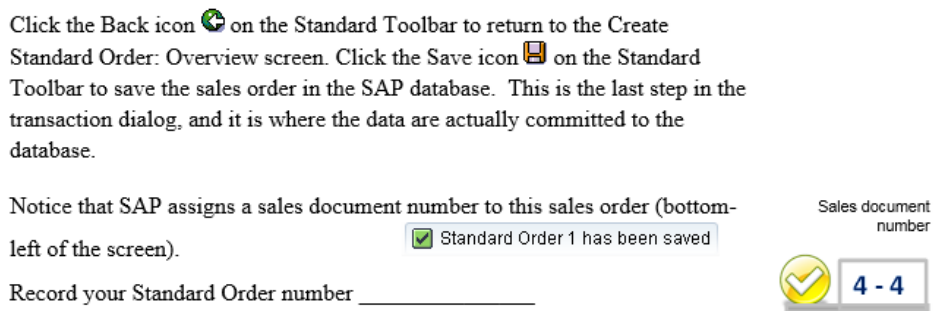

Figure 8. Chapter 4 Narrative and Structured Instructions for Capturing Results with Observed Data Values from a Standard Order IDOC

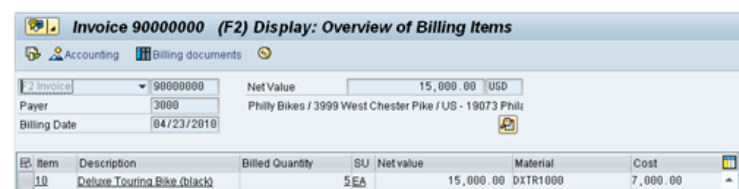

Do a screen capture of the Invoice Display: Overview of Billing Items and put this in your answer sheet. Make sure you include the Status Bar in your screen captures and that it displays your SAP logon name.

Figure 9. Chapter 4 Narrative and Structured Instructions for Capturing Results from a Customer Invoice 


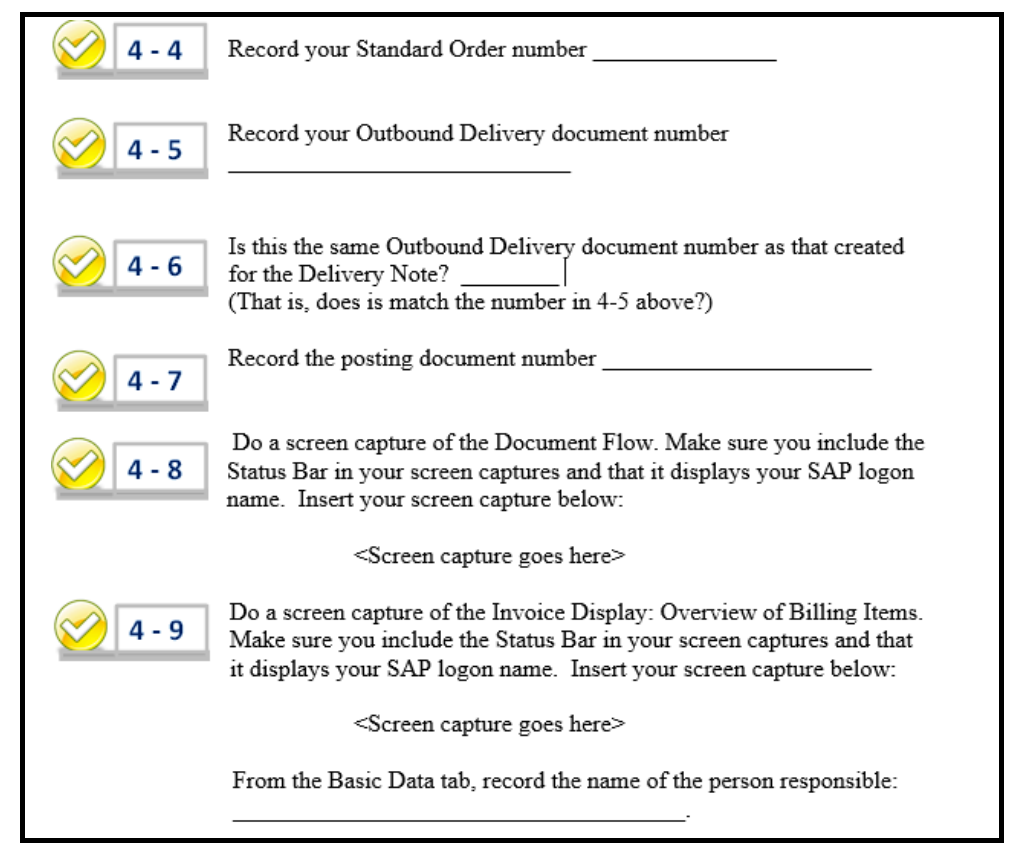

Figure 10. Chapter 4 Student Answer Sheet for Activities 4-4 through 4-9

Overall, the structured learning assignments with coordinating icons furnish a cognitive mapping from the step-bystep keystrokes to the key learning elements of each chapter. They readily organize the assignments for student completion and grading. "Unstructured" learning opportunities are encouraged through the team discussions and narratives. The approach demonstrated here focuses student time on tasks to completing and preparing desired outcome results. By class participation observations [8], there are very few questions on what is to be accomplished and submitted for grading. The students have ample guidance to effectively and efficiently complete these experiential learning assignments.

\section{ERPsim SIMULATION DECISION MAKING}

The decision making segment of the IBE course encompasses use of the ERPsim Simulation [12]. ERPsim is available globally with both the simulator and its related course materials provided by HEC Montreal and coordinated by the SAP UA [14]. The IBE course embraces the use of the ERPsim Manufacturing Introduction and Advanced simulations. ERPsim is a team-based activity with team sizes of four to six team members. The number and size of the teams depends on the number of students enrolled in a class. These simulations transpire over the second two-thirds of the course and culminate with a project report that summarizes the team's strategy and explains their results. ERPsim uses simulated quarters which have a typical clock time of about 30 minutes. For each quarter, a team reviews its business situation and prepares initial decisions that are input to a live SAP ES client. The client dataset is prepared for a particular simulation. This preparation occurs prior to the first quarter only. All succeeding quarters continue with the results obtained by each team in the immediately preceding quarter. The general ERPsim arrangement and student's perceived learning from this experience are reported by Hayen and Holmes [9] [10]. The overall student processes of a simulated quarter are (1) analyze the current business results, (2) prepare the decisions to be input at the beginning of the simulated quarter and a strategy for changes during the quarter, (3) execute the planned decisions during the simulated quarter (this is the actual running of the simulation), and (4) evaluate the results at the termination of the quarter. This simulation cycle is repeated for up to eight quarters. There is instructor variation in determining the appropriate number of simulated quarters to align with course learning objectives.

The structured learning tools for the ERPsim focus on the simulation cycle with its business analytics and decision making. There is much less involvement with fundamental transactions sets such as that for CO2C. Those lowerlevel transactions are carried out by an "ERPsim robot." That is, those transactions are performed, but not by the 
students. An ERPsim Job Aid furnishes the step-by-step keystroke instructions for the six (6) transaction process and the eight (8) transaction reports deployed in the Manufacturing Introduction simulation. Figure 11 illustrates the keystrokes instructions from the Job Aid for two (2) of the transaction process. The fourteen (14) transactions are introduced during the initial three (3) quarters of the simulation and then applied as needed during the remaining simulation quarters. The purpose here is to gain an understanding of the decision making processes within SAP ES. Clearly, it is not a marathon to see how many different transactions can be executed using step-by-step keystroke instructions.

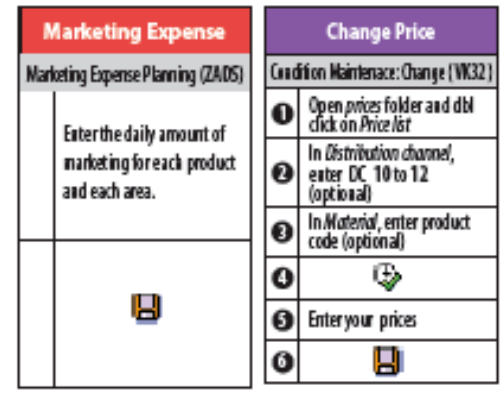

Figure 11. ERPsim Job Aid keystroke Instruction Example [12]

Other than the Job Aid (Figure 11) and a descriptive narrative of the case scenario, an ERPsim simulation is a blank piece of paper for the simulation cycle. That is, there is no outline or other specific guidance concerning the analytics and decision making for the simulation cycles. Rather, the students are expected to draw on their knowledge of finance, accounting, production planning, and other decision making activities from prior business courses or experiences. The purpose of structured assignments is to provide a format for the business analytics and decision making for a simulation cycle. Without this structure, it has been observed that student teams do not adequately rely on their prior business knowledge [8]. Rather, they behave like "Texas hip shooters" with a "fire, aim, ready" approach to their decision making preparation. They have shown a desire to complete their analytics and plan AFTER the simulated quarter has ended. Of course, this defeats the purpose of the analytics and planning. Structured assignments focus on changing this mental approach to the ERPsim simulation and carries with it the requirement for students to submit their analytics and plan BEFORE the start of a simulated quarter. This reinforces the managerial perspective of preparation for the future simulated quarter. The first and last simulation cycles are different from the other cycles. The first cycle has no prior quarter data to analyze, but is driven by the knowledge of the students from their introduction to the simulation. The last cycle analytics does not result in decisions for another cycle. It is just the analysis of the result from that cycle. If the simulation occurs over $\mathrm{n}$ cycles, then cycles 2 through $\mathrm{n}-1$ have the same analysis of prior quarter results and decision preparation for the next cycle. The structured assignments presented here focus on cycles 2 through n- 1 .

The structured assignment is organized as a three (3) page Word document that serves as a template to guide student teams in recording their analytics and planned decisions. The document is arranged in five (5) sections as depicted in Figures 12,13 and 14. Figure 12 is a template for a business SWOT (strengths, weaknesses, opportunities, and threats) analysis of a team's company and of its key competitors. It is designed to examine both internal company data and external business sector data. The structured requirements for supporting data are to avoid situations where a team may report a value as "high" or "low." It forces a focus on what is meant by "high" or "low." Without this guidance, teams have been observed to use more vague qualitative terminology to explain their analytics. For these reasons, a structured assignment document is necessary to elicit this analysis in preparation for an ERPsim simulation quarter.

Figure 13 provides structure for determining the initial quarter pricing for each of the materials manufactured. Student teams need this advance planning and its related discussion prior to the actual simulated quarter. They also plan their strategy for making pricing changes during the simulated quarter. These are specified for each Distribution Channel, which is an SAP ES org structure unit. The material column contains the product number or identifier used in the SAP ES system. Material is the database field name for products, which cannot be changed in the configuration of an SAP client database. Figure 14 lays out the initial marketing plan for the simulated quarter 


\section{Issues in Information Systems \\ Volume 16, Issue II, pp. 17-26, 2015}

and includes the assigned task responsibilities for each team member. The marketing plan is the advertising expenditures in each of the ERPsim marketing regions or areas. The marketing areas are different from the Sales Areas, which are SAP ES org structure units. Regardless, this is the level at which teams plan their strategy and furnish their decisions to the SAP ES client during the simulated quarter. During the quarter, the task responsibilities assignment is very important. The ERPsim is designed for interaction by a management team, where each team member is responsible for a particular task. Frequently, those tasks relate to the transactions of the ERPsim. Different team members focus on the different reports and maintain a continuous dialog with the other team members in responding to changes in the sales and production of their products. This structure causes teams to concentrate on primary features of the ERPsim so as to improve their performance. Teams must work in this manner as one team member cannot enter all the required data and observe all the results while the other team members are merely observers. A fully participative team is necessary to handle the breath of the processing requirements.

A. Your Team (Company)

Strengths \& Supporting Data (Internal / External)

(Here Internal is data about your company, and External is data about your competitors or the overall market)

Weaknesses \& Supporting Data (Internal / External)

B. Key Competitors

(Use this section after quarter 1)

Who are your key competitors?

For your top 2 competitors:

Key Competitor \#1:

Strengths \& Supporting Data
C. Your Action Plans \& Changes to Your Strategy

These include your initial decisions that your team inputs for use at the beginning of Quarter 2 .

Initial Pricing for Distribution Channels 10 and 12

\begin{tabular}{|c|c|c|c|}
\hline Material & Material Description & \begin{tabular}{|c|}
$\begin{array}{c}\text { Distribution } \\
\text { Channel }\end{array}$ \\
\end{tabular} & Price \\
\hline \$\$-F01 & $1 \mathrm{~kg}$ Nut Muesli & 10 & \\
\hline$\$$ \$-F02 & $1 \mathrm{~kg}$ Blueberry Muesli & 10 & \\
\hline \$-F03 & \begin{tabular}{|l}
$1 \mathrm{~kg}$ Strawberry Muesli \\
\end{tabular} & 10 & \\
\hline \$\$-F04 & \begin{tabular}{|l}
$1 \mathrm{~kg}$ Raisin Muesli \\
\end{tabular} & 10 & \\
\hline \$\$-F05 & $1 \mathrm{~kg}$ Original Muesli & 10 & \\
\hline$\$ \$-F 06$ & 1kg Mixed Muesli & 10 & \\
\hline \$\$-F01 & $1 \mathrm{~kg}$ Nut Muesli & 12 & \\
\hline \$\$-F02 & $1 \mathrm{~kg}$ Blueberry Muesli & 12 & \\
\hline$\$ \$-F 03$ & 1kg Strawberry Muesli & 12 & \\
\hline \$\$-F04 & 1kg Raisin Muesli & 12 & \\
\hline$\$ \$$-F05 & \begin{tabular}{|l}
$\mathrm{kg}$ Original Muesli \\
\end{tabular} & 12 & \\
\hline \$\$-F06 & 1kg Mixed Muesli & 12 & \\
\hline
\end{tabular}

Describe your plan for changing your prices throughout the quarter:

Figure 13. Quarter Initial Pricing Decisions for Manufacturing Introduction Simulation
Figure 12. Quarter analytics for Manufacturing Introduction Simulation

\begin{tabular}{|c|c|c|c|c|}
\hline \multicolumn{5}{|c|}{ Initial Marketing Plan (Daily Amounts) } \\
\hline Material & Material Description & North & South & West \\
\hline$\$ \$-F 01$ & $1 \mathrm{~kg}$ Nut Muesli & & & \\
\hline$\$$ \$-F02 & $1 \mathrm{~kg}$ Blueberry Muesli & & & \\
\hline$\$ \$-F 03$ & $1 \mathrm{~kg}$ Strawberry Muesli & & & \\
\hline$\$ \$-F 04$ & $1 \mathrm{~kg}$ Raisin Muesli & & & \\
\hline$\$ \$-F 05$ & $1 \mathrm{~kg}$ Original Muesli & & & \\
\hline$\$ \$-F 06$ & $1 \mathrm{~kg}$ Mixed Muesli & & & \\
\hline \multicolumn{5}{|c|}{ Describe your plan for changing your marketing (advertising) amounts throughout the quarter: } \\
\hline \multicolumn{5}{|c|}{ Team member responsibility assignments: } \\
\hline \multicolumn{3}{|c|}{ Responsibility } & \multicolumn{2}{|c|}{ Team member assignment } \\
\hline \multicolumn{5}{|c|}{ Maintain prices } \\
\hline \multicolumn{5}{|c|}{ Maintain marketing expenses (advertising) } \\
\hline \multicolumn{5}{|c|}{ Monitor inventory } \\
\hline \multicolumn{5}{|c|}{ Check sales order report } \\
\hline \multicolumn{5}{|c|}{ Monitor sales summary report } \\
\hline \multicolumn{5}{|c|}{ Monitor market report } \\
\hline \multicolumn{5}{|c|}{ Analyze sales summary \& market results } \\
\hline \multicolumn{5}{|c|}{ Monitor financial results } \\
\hline Release $\mathrm{pr}$ & duction & & & \\
\hline
\end{tabular}

Figure 14. Quarter Initial Marketing Expenditure Decisions for Manufacturing Introduction Simulation and Team Member Task Responsibilities 


\section{SUMMARY AND CONCLUSIONS}

These results suggest that an IBE course using the SAP ECC enterprise software and the SAP ERPsim simulations can enhance the learning of the integration of business processes, their related transactions, and decision-making. A number of positive effects are observed with this deployment of structured assignments which support cognitive learning. There are virtually no student questions about what is to be done in completing a student's assignments and submitting them for grading. The expectations of the results from the GBI transaction processing component of the IBE course are clear and unambiguous. For the ERPsim component of the course, students are better prepared for each simulated quarter. They have a clear assignment of task responsibilities which coordinates and improves their team performance. This all collaborates the active learning orientation of this course through the deployment of structured assignments to sustain cognitive learning styles. While prior research has measured student learning of business process, future research should be directed to measuring student responses to the structured assignment approaches, such as those described here.

\section{REFERENCES}

1. Adamski, J., Finnegan, K., \& Scollard, S. (2014). Comprehensive Microsoft Access 2013: New Perspectives, Boston, MA: Course Technology, Cengage Learning. ISBN-978-1-285-09920-0

2. Antonucci, Y. L., Corbitt, G., Stewart, G. and Harris, A. L. (2004). Enterprise Systems Education: Where Are We/ Where Are We Going? Journal of Information Systems Education, 15(3), 227-234. .

3. Cate, T., \& Dynan, L. (2010). Structure writing assignments as pedagogy: teaching content, enhancing skills. Journal of Applied Economics \& Policy, 29(1), 47-60.

4. DePaolo, C. A., Sherwood, A. L., \& Robinson, D. F. (2009). Student reactions to assignment structure: examining the influence of cognitive style. Academy of Educational Leadership Journal, 13(4), 61-80.

5. Hayen, R. L. (1994). Comprehensive Lotus 1-2-3 Release 4 for Windows, Boston, MA: Course Technology.

6. Hayen, R. L. (1997) SAP R/3 enterprise software: an introduction, New York, NY: McGraw-Hill Irwin.

7. Hayen, R. L. (2013). SAP Enterprise Software Introductory Course: A New Paradigm, Proceedings $53^{\text {rd }}$ IACIS Conference, 54-55.

8. Hayen, R. L. (2015). [SAP Integrated Business Processes]. Raw research data.

9. Hayen, R. L. and Holmes, M. C. (2014a). SAP Enterprise Software Learning Experience in China. Journal of Business and Educational Leadership, 5(1), 81-90.

10. Hayen, R. L. and Holmes, M. C. (2014b). SAP Enterprise Software in Curriculum Integration. Issues in Information Systems, 15(1), 141-148.

11. Hayen, R. L., Vetter, D., \& Huang, Z. (2007). Using ERP in Curriculum Integration: A Case Study. Issues in Information Systems, 8(1), 204-210.

12. HEC Montreal. (2013). ERPsim Lab. Available: http://erpsim.hec.ca/learning/ April 17, 2013.

13. McKinney, E. H. \& Kroenke, D. M. (2013). Essentials of Processes, Systems, and Information with SAP Tutorials. Upper Saddle River, NJ: Prentice Hall.

14. SAP AG University Alliance. (2013) Introduction to SAP ERP using Global Bike Inc. 2.11. Available: https://cw.sdn.sap.com/cw/docs/DOC-153068.

15. Therrell, J. A. (2012). Personal interview. Director, Faculty Center for Innovative Teaching. (January 10).

16. Veltri, N. F., Webb, H. W., Matveev, A. G., \& Zapatero, E. G. (2011). Curriculum mapping as a tool for continuous improvement of IS curriculum. Journal of Information Systems Education, 22(1), 31-42.

17. Weidner, S. (2011). Global Bike Inc. 2.11, SAP University Alliances. 